\title{
Chagas Disease Treatment Efficacy Biomarkers: Myths and Realities
}

\author{
Elizabeth Ruiz-Lancheros, Eric Chatelain, and Momar Ndao
}

\begin{abstract}
Chagas disease (CD), caused by Trypanosoma cruzi, affects millions of people worldwide. Although CD R\&D has made progress during the last decade, clinicians and general practitioners are still facing the same challenge, i.e., the lack of adequate markers of clinical cure, hindering assessment of new drug efficacy in clinical trials and counseling of patients about treatment outcome. To date, no new markers have been validated as surrogates of seroreversion - the only marker of parasitological cure which is itself considered to be a surrogate of clinical benefit. T. cruzi DNA detected using PCR cannot currently be considered as a surrogate of seroconversion. Much emphasis has been placed on different T. cruzi antigens but no definite proof of correlation between titers, as determined by serology at a given timepoint, and seroreversion has been shown. Thanks to the improvement of analytical methods and the application of new methodologies, the identification of potential new markers is being facilitated, and some of these are progressing. However, there is a long journey from the identification of a potential biomarker to its clinical validation and acceptance by the regulatory authorities that requires a common effort from the entire Chagas community.
\end{abstract}

\footnotetext{
E. Ruiz-Lancheros $\cdot$ M. Ndao $(\square)$

National Reference Centre for Parasitology, Research Institute of the McGill University

Health Centre, Montreal, QC, Canada

e-mail: momar.ndao@mcgill.ca

E. Chatelain $(\bowtie)$

Drugs for Neglected Diseases initiative (DNDi), Geneva, Switzerland

e-mail: echatelain@dndi.org
} 


\section{Introduction}

The last decade has seen an increase in the number of clinical trials assessing the potential of new drugs for Chagas disease (CD), focusing specifically on repurposed azoles. One of the main issues facing clinical researchers in the field, however, is the absence of clearly defined markers of clinical cure, due to the complexity and long development time of the disease. This fact, among others, has hampered efforts toward the development of new drugs for $\mathrm{CD}$. The scope of this review is not to present an extensive overview of all the potential markers for assessment of treatment efficacy described so far, as this has already been done [1-3]. Instead, we focus on the current needs and challenges in this specific area, describe new technologies that have been applied to the identification of potential markers of interest and propose the steps that we consider should be taken in order to tackle this important issue.

Indeed, we believe that a concerted joint effort by the CD community is essential in order to gain a better understanding of how to define a biomarker for CD and how then to further develop and validate it, in order to answer this very complex and demanding research question. This is not only necessary to be able to run clinical trials for the registration of new drugs but also so that general practitioners will be able to inform patients about the outcome of their treatment.

\section{Chagas Disease Overview}

CD, also known as American trypanosomiasis, and its etiological factor, Trypanosoma cruzi, were discovered more than a century ago by Carlos Chagas [4]. Since then, CD epidemiology has changed; although still endemic in Latin America, the disease has spread into non-endemic countries due to population migration and has become a global public health issue [5-8]. CD is the most common cause of infectious cardiomyopathy worldwide [9]. Around 6-7 million people are infected worldwide and 10,000 die annually $[10,11]$. The disease presents in two main phases: the acute phase, which is asymptomatic and typically undetected and lasts for a couple of months during which the parasite is readily identified through blood examination, and the chronic phase, which can last for decades while the infection is controlled by the immune system and the parasite is hardly detectable. While most infected patients in the chronic phase will remain asymptomatic, a certain proportionbetween $10 \%$ and $40 \%$ - eventually develop symptoms, mainly cardiomyopathies and in certain cases digestive tract megasyndromes or both [12]. The major causes of mortality in these patients are progressive heart failure and sudden death [13].

There are two treatments currently available, benznidazole (Abarax/ELEA and Rochagan/LAFEPE) and nifurtimox (Lampit/Bayer), which are old nitroheterocyclic trypanocidal drugs. Although these drugs have been shown to be efficacious in both phases of the disease, particularly in children, their use is limited due to side effects occurring during treatment and impeded access to medication $[14,15]$. There is an urgent need for new and safer drugs for CD. 


\section{Disease Progression and Treatment Efficacy Assessment: Current Challenges and Future Needs}

A major hurdle for the clinical development of new drugs for CD is the absence of an adequate test that can assess successful treatment or show clinical benefit in a timely manner. The definition of cure criteria for $\mathrm{CD}$ has been subject to debate; the complicated development and pathology of the disease, coupled with the complexities of the parasite life cycle and its interactions with the host, make it a very difficult task to determine such criteria. Clinical cure criteria are very often discarded as they are considered to be too difficult to achieve and possibly because of a lack of understanding of the slow evolution of the disease from asymptomatic stage to cardiomyopathy and/or megacolon [16]. Another issue is the lack of consensus on the assessment of treatment efficacy and inadequate tools to address it [17].

Although there is no absolute proof in patients that parasitological cure is synonymous with clinical cure, i.e., halting the progression of the disease toward cardiac or gastrointestinal symptoms, there is a consensus that parasite persistence is needed for the development of CD. All current CD drug development efforts are therefore focused on strategies to eliminate T. cruzi from the human body. The only way to assess drug treatment efficacy is to use serological tests showing the disappearance of $T$. cruzi antibodies (seroreversion, synonymous with parasitological cure). This is clearly a major challenge, since seroreversion can take decades to occur in treated adults, if it occurs at all. This makes assessment of parasitological cure with the currently available tools in this category of patients complicated, if not impossible, and thus seroreversion is not useful as a clinical endpoint in clinical trials. There is, therefore, a need to identify surrogate markers for the absence of parasites that are quicker and more sensitive than seroreversion. A surrogate endpoint of a clinical trial is a laboratory measurement or a physical sign that is used as a substitute for a clinically meaningful endpoint that measures directly how a patient feels, functions, or survives. Changes induced by a therapy on a surrogate endpoint are expected to reflect changes in a clinically meaningful endpoint [18].

The need for surrogate markers of parasitological cure is further highlighted by the recent FDA approval of benznidazole (BZN) monotherapy exclusively for the treatment of chagasic children between 2 and 12 years of age [19, 20]. In T. cruziinfected children, seroreversion can be observed fairly quickly, within months to a few years following treatment. The FDA approval of BZN for children was based on seroreversion observed in around $50 \%$ of children $[21,22]$.

Another important feature of CD is the fact that not all T. cruzi-infected patients will develop the disease - in the literature it is typically stated that around 10-40\% of infected patients will develop symptoms of the disease [12] — and that possible host factors for susceptibility are not well understood [23]. It would be useful to identify markers of disease progression that could be used to predict which $T$. cruzi-infected people are likely to develop the disease, as treatment could then be focused on people most at risk.

Efforts to understand this phenomenon and to identify patterns or indicators that could be used to categorize patients at risk of developing the disease have so far not 
been successful. Preliminary attempts have been made to identify candidate genes associated with the progression of the disease. Results from a genome-wide association study (GWAS) using the well-established REDS-II cohort of Chagas patients suggested that both cardiovascular- and immune-related polymorphism in some genes of interest could be associated with a genetic predisposition to chronic Chagas cardiomyopathy [24]. Another study found an association between HLA haplotype and resistance to chronic Chagas disease [25]. A recent study showed a potential association between variations in the inflammasome, particularly in NLRP1 and CARD11, and chronic Chagas cardiomyopathy [26]. Although all these studies suffer from the low number of patients used in the analysis, this is certainly an area of research that merits further investigation.

\section{CD Biomarker Identification for Treatment Efficacy Assessment and Next Steps: The What(s) and How(s)}

There is a need to identify a surrogate marker for the absence of parasites that is quicker and possibly more sensitive than seroreversion. Efforts to identify new potential biomarkers, comparing, for example, samples from healthy people and Chagas patients, can lead to a substantial amount of data that is not always easy to interpret and analyze. Even when potential markers of interest are identified, there is still a long way to go to ensure that these putative markers will be useful in practice [27]. This will include analytic (validation of an assay for the marker of choice) and clinical validation of the marker as well as regulatory acceptance.

It becomes very important therefore to define the attributes that should be required for a biomarker, in particular those related to the methodology used for the analysis of a chosen marker and its suitability in the field, its level of sensitivity and selectivity, and the current level of validation according to the types and number of samples tested, to name but a few criteria. The definition of a target product profile (TPP) for a biomarker and its associated test should clarify these points early on in order to avoid focusing work and testing on a marker of interest for which no suitable test could be available for routine analysis. A tentative TPP for Chagas disease assessment of treatment response has been described but seems to be biased toward the use of PCR [28]. A more general biomarker TPP was highlighted by Pinazo et al. in their biomarker systematic review [2].

Another point for consideration is related to the quality and type of samples used to identify and validate biomarkers. Specimens from patients at different stages of the disease and from healthy people are critical tools for this and for the development of better tests. The appropriate detailed information and handling procedure to be followed are defined in local or international guidelines, and standardization of specimen collection methodologies is critical [29]. Indeed, technical aspects such as the anticoagulant used, sample processing time, processing and storage temperatures, and thaw/freeze cycles are all variables that can impact the quality of specimens and their stability over time, thereby having an impact on analysis results [30]. 
Finally, the design of clinical trials from which the specimens originate and which are used for the identification and validation of potential biomarkers should be considered very carefully.

\section{Pros and Cons of Currently Proposed Biomarkers of Cure for CD}

Several CD biomarkers have been suggested and used to discriminate between CD-infected and CD-non-infected individuals when assessing chemotherapy in cohort studies with adults or children and to establish disease progression in CD patients. However, very few of them show high sensitivity, have been systematically studied, or could be used to determine treatment efficacy. In addition, not many would pass the quality criteria mentioned above (see Sect. 4). All the CD biomarkers suggested so far have been reviewed by different authors (see [1, 3]). In 2014, a systematic review by Pinazo et al. proposed 25 potential biomarkers for the evaluation of therapeutic efficacy [2]. Requena-Méndez et al. also reviewed some blood-derived biomarkers useful for disease progression and cure [31]. Here we describe the pros and cons of some of these biomarkers and also some promising new markers with the potential to be surrogate endpoints. A summary of candidates is presented in Table 1 .

\subsection{Parasite DNA Amplification and Antigens for Serological Tests}

Parasite detection in blood by PCR and the evaluation of antibodies by serology are the main techniques used to monitor CD treatment response in patients and in CD clinical trials. The evaluation of treatment efficacy is affected by their limitations, which have been recognized as Achilles' heel of clinical trial outcomes. PCR has shown promising results for the assessment of therapy failure; a positive result clearly evidences failure to clear the parasite and thus ineffective treatment [57]. However, a negative PCR does not guarantee the absence of parasite and cannot confirm parasite clearance. False negatives occur due to fluctuations in parasitemia, the isolation of parasite in tissue or organs, and the intrinsic limit of detection of PCR and qPCR techniques [58]. Other distinct factors may contribute to the overall performance of PCR assays: the size of the serum sample for parasite DNA extraction, the sample collection tubes, the different PCR assay conditions, and the algorithm used to classify results can affect the evaluation of the samples, as was demonstrated by Wei et al. [59] for the STOP CHAGAS clinical trial that evaluated posaconazole for the treatment of CD [60]. Nevertheless, PCR is a promising tool that can be easily performed in clinical settings and used for clinical trials; thus, the investment in improving PCR methodologies is worthwhile. The CD community must focus on suitable strategies for parasite DNA extraction in lower sample volumes, the equivalence between blood and tissue parasitemia; the reduction of false 


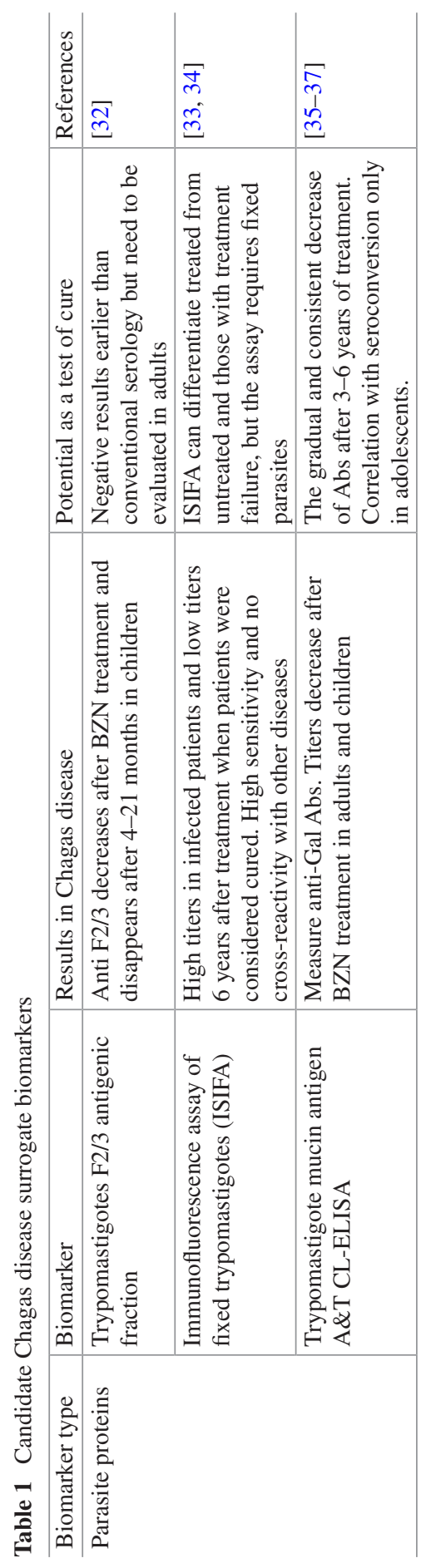




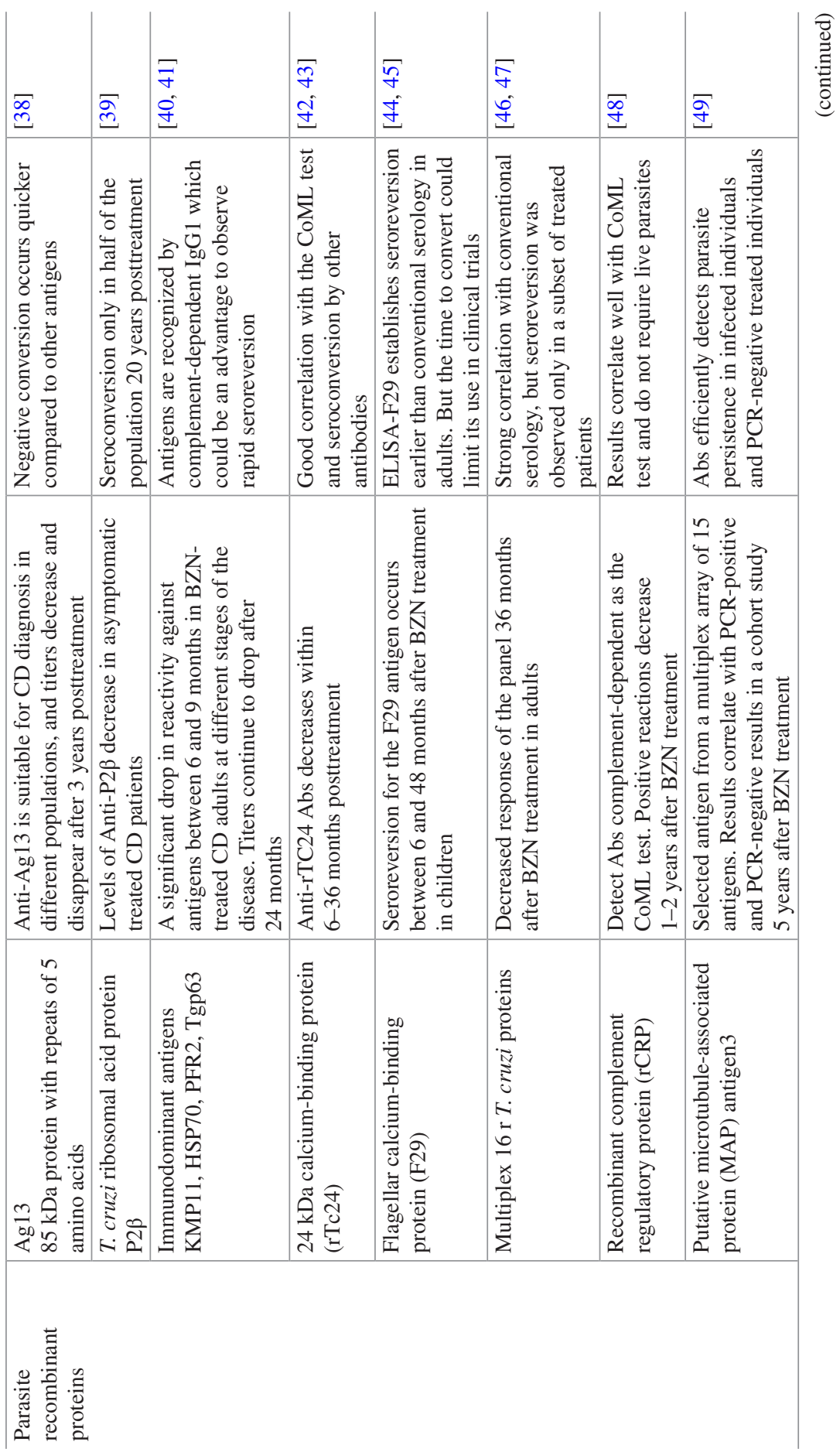




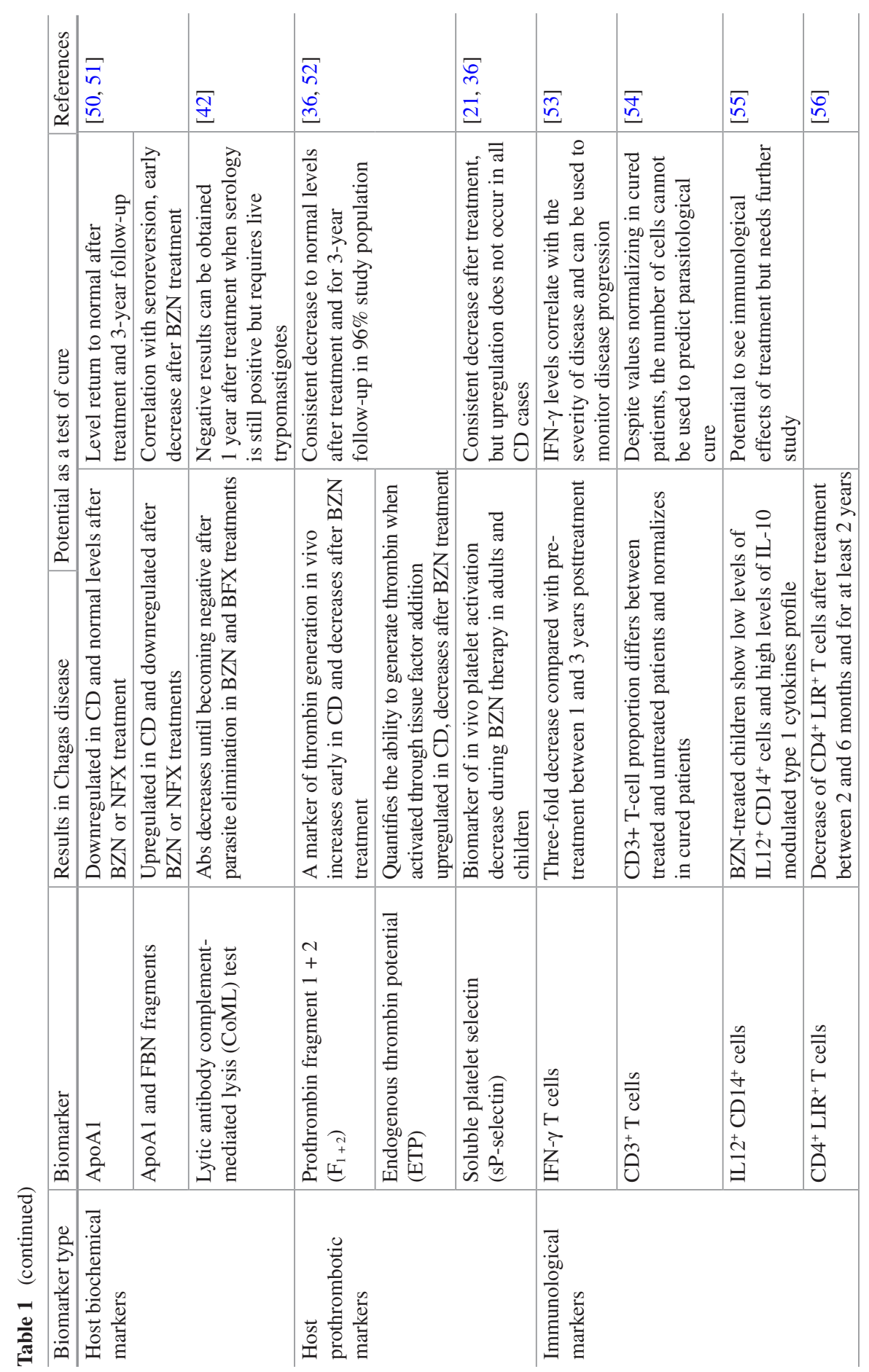


negatives, as well as the validation and standardization of PCR assays; and the correlation of PCR readouts with seroreversion.

Conventional serology with different parasite antigens is commonly used for CD diagnosis and to evaluate antibody titers against $T$. cruzi after chemotherapy. Due to the long-term persistence of specific antibodies that are detected by serological tests, chronically infected patients must be followed up for several years after treatment until they can be considered cured using seroreversion as a measurement of parasite clearance [33]. The current criteria of cure consist of two nonreactive conventional serological assays with parasite antigens that are commercially available as diagnostic kits in endemic countries. The probability of cure might also be predicted by a decrease in antibody titers for T. cruzi over time, but this will depend on the specific antibody and the status of the disease before treatment [57]. However, serodiscordance remains a challenge in Chagas disease diagnosis and raises the question of the reliability of serology tests relying on one specific antigen depending on the region and patient stage [61-63].

Of all the $T$. cruzi antigens published in the literature, only a few have been evaluated in the long term and used to predict treatment efficacy. Antigens obtained directly from $T$. cruzi preparations as the F2/3 antigenic fraction (isolated from trypomastigotes) have been used to assess cure in children with congenital transmission [32]. Anti-F2/3 antibodies become negative 4-21 months after BZN treatment and earlier than conventional serology, suggesting that they may provide an earlier marker of cure. Likewise, Andrade et al. have shown that a chemiluminescent enzyme-linked immunosorbent assay (CL-ELISA) with a trypomastigote mucin antigen (A\&T) successfully assesses treatment efficacy in BZN-treated adolescents [35]. When measured as negative A\&T CL-ELISA seroconversion, $88.7 \%$ of the treated group were cured after 6-year follow-up. Using this assay, the BZN efficacy in children and adolescents by per-protocol analysis and by intention-to-treat approach was $84.7 \%$ and $64.7 \%$, respectively. F2/3 and A\&T antigens obtained from parasites seem to be candidate surrogate biomarkers, but their use in adult studies needs to be further evaluated since the reduction in titers and seroreversion can take longer. Pinazo et al. have shown that A\&T CL-ELISA remains positive for 3 years after treatment in an adult population [36].

Since obtaining pure proteins from the parasite can be laborious, several recombinant proteins have been produced and tested for detecting anti-T. cruzi antibodies in ELISAs and immunoblots. Most of the specific antibodies against recombinant proteins are good at discriminating CD individuals from healthy controls and useful for monitoring patients after treatment. Recombinant proteins such as F29 (flagellar calcium-binding protein); P2 $\beta$ (ribosomal acid protein); KMP11, HSP70, PFR2, and Tgp63 (immunodominant antigens); Ag13 (85 kDa protein with repeats of $5 \mathrm{aa}$ ); and a multiplex of $16 \mathrm{~T}$. cruzi proteins have been used to assess treatment efficacy and to attempt to predict cure (see Table 1).

Anti-F29 decreases quickly after BZN treatment in children and seroconverts in $62.1 \%$ of cases after 48 months [44]. Fabbro et al. have shown that Anti-F29 may take up to $14.5 \pm 5.7$ years to seroconvert after BZN or nifurtimox (NFX) treatment in adults but predicts cure earlier than conventional serology (22 \pm 4.9 years $)$ [45]. 
By contrast, anti-P2 $\beta$ can take more than two decades to seroconvert in treated asymptomatic patients despite a reduction in titers compared to their initial values [39]. Anti-KMP11, HSP70, and PFR2 decrease rapidly a few months (6-9 months) after BZN treatment in more than $70 \%$ of CD patients and continue to decrease during the 24 months posttreatment follow-up period [40]. This is perhaps because KMP11 and HSP70 are mainly recognized by IgG1 complement-dependent antibodies [41]. Anti-Ag13 also has shown a constant decrease in titers compared with other antigens and seroconverts in 6/9 patients after 3 years of treatment [38]. Finally, a panel of 16 proteins in a multiplex bead assay has shown a strong correlation with conventional serology tests in a short-term follow-up of 53 BZN-treated patients [46, 47]. Despite the evidence gathered so far, longer follow-up and tests in larger populations are needed to select the best Ag/Abs pairs that can be used to evaluate treatment efficacy in clinical trials, regardless of the type of treatment or the patient's disease status.

In the search for the ideal antigens and antibodies, Zrein et al. used an innovative multiparametric screening technology to identify antibodies that could be used as surrogate biomarkers [49]. After evaluating 15 antigens in a multiplex serology assay, Antibody 3 (Ab3), which recognizes T. cruzi putative microtubule-associated protein (MAP) (Antigen 3), showed a strong correlation (92\%) with PCR-positive results in treated and untreated CD patients from the SaMi-Trop cohort study [64]. More importantly, Ab3 could discriminate PCR-positive patients from PCRnegative treated patients (AUC 0.74). Ab3 efficiently detected parasite persistence in most of the T. cruzi-infected individuals and detected a large number of parasite persistent cases within the PCR-negative group, which shows this assay to be even more informative than PCR [49]. These results suggest that Ab3 could be a good surrogate biomarker; however, Ab3 titers should be evaluated before treatment and in a non-infected population. Validation of other cohort studies, quantitative evaluation of serology, and following titers until seroconversion will determine if parasitological endpoints can be predicted with this antibody. Its usefulness for evaluating treatment efficacy in clinical trials will also depend on a quick change in Ab3 titers after treatment.

Detection of complement-dependent lytic antibodies seems to be an alternative to the detection of specific anti-T. cruzi antibodies. These lytic antibodies can be detected either by complement-mediated lysis (CoML) test or by indirect immunofluorescence (IIF). The antibodies appear as soon as 20 days post-infection and disappear as early as 1-year post-chemotherapy [42]. In the 10-year follow-up of a study of CD patients treated with BZN or NFX, patients showed consistently negative CoML test results at 6 to 33 months posttreatment despite positive IIF and conventional serology and thus were considered cured [65]. The disadvantage of this approach is the need for living infective trypomastigotes, which is not practical for clinical trials. One epitope of the lytic antibodies contains a high molecular mass (160 kDa) protein, T. cruzi complementary regulatory protein (CRP). Meira et al. found a good correlation between the CoML test and an ELISA using a recombinant CRP [48]. In a cohort study with 31 CD patients, both tests showed the same significant reduction in the number of positive samples over a period of 4 years after treat- 
ment [48]. However, evaluation of a bigger population is needed to confirm if this ELISA could replace the CoML test and be used to establish parasite clearance [42]. A recombinant calcium-binding protein $(\mathrm{rTc} 24)$ has shown a good correlation with CoML test in ELISA and immunoblot, but its potential as a surrogate endpoint has to be further investigated [43].

\subsection{Host Biochemical Molecules}

Since $T$. cruzi is an intracellular parasite that produces a chronic infection, biochemical molecules from the host such as metabolites, proteins, immunomodulators, and cell surface proteins can be affected due to infection and thus may be potential CD biomarkers. In addition, host biochemical molecules can be better surrogate biomarkers than antibodies against $T$. cruzi antigens or DNA amplification techniques, since their evaluation will not depend on the persistence of antibodies or the direct detection of parasites.

In the search for indicators of parasite signature, our group performed the first serum protein analysis of CD patients using mass spectrometry [50]. We used serum fractionation to evaluate both high- and low-abundant serum proteins and surfaceenhanced laser desorption ionization time-of-flight mass spectrometry (SELDI-TOF MS) for intact protein analysis [66, 67]. In a panel of 435 sera from Venezuelan asymptomatic CD patients and healthy controls (HC), we identified 18 host proteins that were statistically different between the $\mathrm{CD}$ and control populations. To select biomarkers with the greatest discriminatory power, we used a biomarker pattern software to generate candidate decision trees. Five host markers showed high sensitivity (89\%) and specificity $(100 \%)$ and could distinguish asymptomatic CD adult patients from HC. Biomarkers were identified by MS/MS analysis as full-length and fragments of the apolipoprotein-A1 (ApoA1) as well as a fragment of fibronectin (FBN) [50]. It is worth mentioning that our success in detecting and identifying these biomarkers was due to our innovative intact protein approach, also known as "top-down proteomics."

We used the same strategy to search for biomarkers in a Bolivian CD population and to predict cure after treatment with NFX [51]. After comparing the serum proteins of $\mathrm{CD}$ vs $\mathrm{HC}$, the same candidate biomarkers were identified, demonstrating the reproducibility of the approach across the South American population, an important factor considering the variety of infective $T$. cruzi strains in patients in this region. In addition, we observed that ApoA1 and FBN fragments were significantly upregulated in chronic or asymptomatic $\mathrm{CD}$ subjects compared to $\mathrm{HC}$ and 3 years after NFX treatment returned to levels similar to those seen in HC. In contrast, fulllength ApoA1 was downregulated in CD individuals compared to $\mathrm{HC}$ and returned to normal levels during the follow-up period. All patients were seropositive 3 years after treatment, but using these biomarkers, we were able to predict an overall cure rate of $43.2 \%$. These results suggest that these biomarkers might be useful in assessing treatment efficacy in CD patients and could lead to the development of a test of cure [51]. Following this lead, we have developed a proteomics-based immunoblot 
that detects ApoA1 and FBN fragments in CD patients. This is a successful translation of proteomics-based studies into accessible tools for bench diagnosis. Results from these studies confirm these fragments as signatures of the parasite and their great potential as surrogate biomarkers.

\subsection{Host Prothrombotic and Immune Markers}

Host prothrombotic markers have been used to evaluate disease progression in the chronic phase of $\mathrm{CD}$, but they could also be useful for treatment evaluation. In infection, immunothrombosis is activated after the recognition of a pathogen in order to inhibit its dissemination and survival; different infectious agents may cause responses to different degrees. Thromboembolic events are observed in cases of chagasis cardiomyopathy, and an increased risk of peripheral thrombotic phenomena and thrombosis in CD patients without heart failure or structural cardiopathy has been observed. These events can be attributed to the host immune system and to the parasite itself. Of all the biomarkers that can identify a prothrombotic state, markers for clotting activation that have shown the most consistent results are prothrombin fragment $1+2\left(\mathrm{~F}_{1+2}\right)$ and the endogenous thrombin potential (ETP). These markers are elevated in the early stage of the chronic phase and decrease after therapy with BZN [52]. In a more recent study with 99 individuals, Pinazo et al. observed that $\mathrm{F}_{1+2}$ and ETP were abnormally expressed in $77 \%$ and $50 \%$ of infected patients before treatment but returned to, and remained at, normal levels 6-9 months after treatment in $76 \%$ and $96 \%$ of cases, respectively [36]. This data suggests these markers could assess short-term response to treatment; however, normal values can be observed in infected patients, and some patients show qPCR-positive results even when ETP values reach baseline after treatment.

Lastly, different cytokines and cell surface markers have been evaluated in CD patients and proposed as immune markers for disease progression. Within them, $\mathrm{IFN}_{\Upsilon} \mathrm{T}$ cells, $\mathrm{CD}^{+} \mathrm{T}$ cells, IL12 ${ }^{+} \mathrm{CD} 14^{-}$cells, and $\mathrm{CD}^{+}{ }^{+} \mathrm{LIR}^{+} \mathrm{T}$ cells have been studied in $\mathrm{CD}$-treated or CD-untreated populations. $\mathrm{IFN}_{\Upsilon}$ is one of the main cytokines that regulate Th1 immune responses, and it is critical for innate and adaptive immunity against virus and intracellular parasites. High levels of $\mathrm{IFN}_{\Upsilon}$ in peripheral blood mononuclear cell (PBMC) cultures correlate with severity of CD cardiomyopathy and are probably responsible for the strong Th1 response in CD patients with cardiac disease [68]. Laucella et al. have observed that $\mathrm{IFN}_{\Upsilon}$ T-cell levels decrease after BZN treatment between 1 and 3 years posttreatment and become undetectable in almost $50 \%$ of treated patients [53]. Likewise, the proportion of $\mathrm{CD}^{+} \mathrm{T}$ cells differs between treated and untreated patients and normalizes in cured patients without changes in the PBMC phenotype [54]. In patients treated with BZN during the early indeterminate stage, the number of $\mathrm{IL}-12^{+} \mathrm{CD} 14^{+}$cells decreases, and treatment induces an IL-10-modulated type 1 cytokine profile [55]. On the other hand, chronic CD patients have shown increased numbers of CD4 $4^{+} \mathrm{LIR}-1^{+}$among total PBMCs, relative to non-infected individuals, and these numbers decreased after BZN treatment [56]. Although these findings suggest that cell types and their mark- 
ers can be used to assess the influence of treatment, their potential as surrogate biomarkers needs to be further studied.

Nonetheless, immunomarkers can be useful in phase I clinical trials of new drugs. In a mouse immunosuppressed model, the presence of MHC-peptide tetramers, which are specific for $\mathrm{CD}^{+} \mathrm{T}$ cells recognizing a transialidase peptide, was monitored as a biomarker for treatment success [69]. Cured mice show an increased number of $\mathrm{T}$ cells displaying a central memory phenotype $\left(\mathrm{T}_{\mathrm{CM}}\right)$ with surface markers CD62L and CD127, these markers are not present in $\mathrm{T}_{\mathrm{CM}}$ and $\mathrm{T}$ effector memory cells $\left(\mathrm{T}_{\mathrm{EM}}\right)$ in non-treated mice, and the phenotype could be used to determine treatment efficacy and cure [70].

\section{New Developments: A Hopeful Way Forward?}

During the last 15 years, new developments have changed the Chagas biomarker landscape. These developments have included both the emergence of new tools and technologies for the assessment of known/“established" markers (essentially T. cruzi antigens or antibodies) and the identification of potential new markers, in particular markers in the host, for the diagnosis of CD and the assessment of drug treatment efficacy. These include, among others, high-throughput technologies to identify RNA aptamers; new analytical devices such as biosensors; new mass spectrometry and NMR technologies allowing comparative analysis of proteins, metabolites, lipids, and mRNA in serum samples from healthy and infected patients (X-omics); as well as FACS and MRI.

\subsection{Aptamers}

RNA aptamers are short nucleotides that can bind specifically, and with high affinity, to targets in complex protein mixtures, membrane preparations, or whole cells. Their specificity depends on their hydrophobic and ionic interactions with the target as well as on their tertiary structure. Aptamers can be developed in vitro using an iterative procedure known as systematic evolution of ligands by exponential enrichment (SELEX). Without a priori knowing a specific target, this process can select RNA sequences with affinities similar to or lower than those seen with monoclonal antibodies [71-73]. This approach was first explored for CD by Nagarkatti et al. in order to concentrate T. cruzi parasites and facilitate their detection by PCR [74]. Using a whole-cell SELEX strategy, they developed serum-stable RNA aptamers that bind to live $T$. cruzi trypomastigotes with an affinity ranging between 8 and $25 \mathrm{nM}$. The aptamer with the highest affinity, Apt68 $\left(K_{\mathrm{d}} 7.686 \pm 1.63 \mathrm{nM}\right)$, also showed high specificity and did not bind either insect stage epimastigotes of $T$. cruzi, Leishmania donovani promastigotes or Trypanosoma brucei. The authors also demonstrated that Apt68 was able to bind parasites from different strains, when immobilized in the solid phase and at parasite concentrations as low as 0.33 parasites/ml (five parasites in $15 \mathrm{ml}$ ). This approach could be useful for CD diagnosis 
during the early phase of infection (the window period of PCR detection) or during the chronic phase when there is intermittent parasitemia in the blood [74].

More recently, the same group used the SELEX strategy to select aptamers that bind specifically to TESA (T. cruzi excreted-secreted antigens) aiming to develop a new direct non-serological, non-PCR-based assay to detect T. cruzi infection. After ten rounds of selection, Apt-L44 showed specific binding to TESA as well as to $T$. cruzi trypomastigote extract from three different strains but not to epimastigotes, host proteins, or L. donovani proteins. Using biotinylated Apt-L44 in an enzymelinked aptamer (ELA) assay, the aptamer showed specific binding to TESA, and higher levels of binding were observed in the serum of T. cruzi-infected mice compared to non-infected mice. Additionally, Apt-L44 could detect circulating TESA in mice in both the acute and chronic phases. Apt-L44 ELA assay could be used as a qualitative assay in drug screening to detect $T$. cruzi antigens in infected mice and demonstrate that live parasites are present in the host, even if their direct detection in blood by PCR is negative [75].

Increasing the SELEX rounds and the stringency of the conditions, de Araujo et al. found an aptamer (Apt29) with a higher signal for TESA in infected mice and a higher signal-to-noise ratio compared to Apt-L44 [76]. This aptamer was also able to differentiate infected from non-infected mice and predict treatment failure. In infected and chronically infected mice, the TESA levels detected by Apt-29 ELA were reduced upon BZN treatment. However, levels did not return to those seen in non-infected treated mice, suggesting parasitemia was reduced but parasitological cure was not achieved. These results are in agreement with the detection of parasites in the heart and skeletal muscles by PCR and suggest that the assay can be used to assess treatment efficacy in vivo in murine drug discovery models [76]. However, its ability to predict parasitological cure needs to be confirmed. The ELA assay does not need sophisticated equipment or reagents but can be performed in highthroughput formats, and animals do not need to be sacrificed. In addition, aptamers can be used to evaluate patients' serum and can be coupled to different matrices to increase the detection limit, which makes them a promising tool for CD diagnosis and prognosis. Further validation using human specimens is, however, necessary before drawing conclusions.

\subsection{Biosensors}

The application of new technologies and miniaturization have led to new tools, biosensors, that can be applied to the field of Chagas diagnostics and that can help to detect the presence of T. cruzi in serum. A biosensor is an analytical device that converts molecular recognition of a target analyte into a measurable signal via a transducer. Depending on the type of transducer that is employed, they may be electrochemical, acoustic, or optical [77, 78]. To develop a biosensor, a biologically active component needs to be immobilized onto the surface of the transducer; once the target analyte is recognized, a signal response in the sensor is generated, and the 
signal can be amplified and measured in an electronic system that acquires and records the signal [78]. Biosensors are easy to use, give results in real time and require small sample volumes and short assay times, and have a low energy consumption, which make them excellent tools for point-of-care (PoC) units. Furthermore, they are a sensitive and inexpensive technology platform compared with conventional diagnosis technologies. During the last 15 years, different electrochemical (amperometric or impedimetric) and optical sensors have been designed and tested for the indirect or direct (label-free) detection of T. cruzi in serum at acute and chronic stages for CD diagnosis.

In 2011, Pereira et al. optimized an electrochemical immunosensor to quantify IgG T. cruzi antibodies in serum patients using T. cruzi epimastigote membranes. In order to increase the sensitivity and efficiency of membrane immobilization, a screen-printed carbon electrode (SPCE) was used, and gold nanoparticles (AuNPs) were electrodeposited where the T. cruzi antigens were immobilized. The biosensor also uses anti-IgG antibodies coupled to horseradish peroxidase (HRP) and redox reagents to amplify (label) the immunodetection [79]. Their optimized biosensor showed a linear detection of IgG T. cruzi antibodies between 11 and $205 \mathrm{ng} / \mathrm{mL}$ and a detection limit of $3.065 \mathrm{ng} / \mathrm{mL}$. In addition, the microfluid technology used allowed a fast response and short assay time $(26 \mathrm{~min})$. This biosensor is easy to operate and transport, but it still depends on the presence of anti-T. cruzi antibodies to predict infection.

More recently, a similar approach was used to develop a biosensor to detect and quantify anti-T. cruzi IgM antibodies in newborns and infants and to predict congenital CD [80]. In this case, a SAPA (shed acute-phase antigen) was immobilized in a SPCE together with AuNPs. IgM antibodies appear early in the acute phase of T. cruzi infection, and the SAPA has been shown to be a good marker for CD diagnosis by conventional serology. Moreover, anti-SAPA antibodies ( $\operatorname{IgM}$ or $\mathrm{IgG}$ ) have been detected in $90 \%$ of acute chagasic patients and in 7-10\% of chronic patients [81]. This biosensor can distinguish between congenitally infected and non-infected infants when cord blood is tested, the sensitivity is in the $\mathrm{ng} / \mathrm{mL}$ range $(3.03 \mathrm{ng} / \mathrm{mL})$ and the linear response between 10 and $200 \mathrm{ng} / \mathrm{mL}$ [80]. This device could facilitate and speed up the unequivocal diagnosis of congenital transmission, since it does not depend on the detection of parasite in newborns or the clearance of maternal antibodies in infants. To continue its validation, a large set of samples from newborns and infants at different ages needs to be tested.

A biosensor to be used in PoC units for serodiagnosis of infectious diseases was fully developed by Cortina et al. [82]. In this device, antigen-coated magnetic beads are used to detect antibodies in serum samples. Immunocapture is amplified using HRP-conjugated secondary antibodies, and the beads magnetically collected are placed on an electrode surface to detect peroxidase activity amperometrically [82]. For CD diagnosis, recombinant proteins of different T. cruzi antigens (Ag1, Ag36, SAPA, and TSSA) were used to coat superparamagnetic beads and tested with serum samples from CD patients and HC. Results showed that the magnetic beadbased biosensor discriminates infected from non-infected serum with a minimal overlap and excellent signal-to-noise ratio. It also showed a high level of accuracy 
in diagnosis, similar to ELISA and IFA, as well as having similar sensitivity and selectivity [82]. Despite the different steps to be performed during the assay, it can be done in PoC units as it uses an eight-channel portable potentiostat powered by a rechargeable battery. The device is not yet commercialized, but there is potential for its use in the diagnosis of $\mathrm{CD}$ and other parasitic infections.

All the above biosensors detect $T$. cruzi antigens indirectly by peroxidase activity, which requires multiple steps of incubation with a secondary antibody and redox reagents. In contrast, a free-label biosensor that uses optical transducers needs fewer steps and a shorter assay time and still shows high sensitivity. An optical immunosensor (SPRCruzi) with a surface plasmon resonance (SPR) transducer was recently developed for CD diagnosis [83]. SPR sensors use surface plasmons, which are electromagnetic waves that can be excited by light at gold sensor interfaces, to transduce a biochemical interaction. In brief, the interaction changes the SPR baseline, and real-time measurement of specific analytes in unknown samples flushed over the sensor can be performed; for a review, see [77, 84].

To build SPRCruzi, Luz and collaborators used soluble antigens of T. cruzi epimastigotes immobilized on a sensor chip. The biosensor was able to discriminate positive from negative serum, including those infected with other related parasites, and detect antibodies in serum dilutions as high as 1280x. In 2016, the same group tested SPRCruzi with a higher number of positive and negative serum samples and compared their results with conventional serological tests. SPRCruzi showed 100\% sensitivity (cutoff $\triangle \theta \operatorname{SPR} 17.2^{\circ}$ ), $99.6 \%$ global accuracy, and a better specificity (97.2\%) compared to ELISA [80]. Nonetheless, the use of this device is still limited to laboratories since expensive and heavy SPR equipment is required.

Lastly, a CD nanowire electrical sensor based on field-effect transistor (FET) technology was designed last year by Janissen et al. [85]. In FET sensors, the current-carrying capability of a semiconductor is used, and the sensor response is interpreted as a result of a shift in the threshold voltage of the field-effect structure [77]. In the Janissen et al. device, anti-T. cruzi IBMP8-1 antibodies were immobilized on a surface using a biocompatible ethanolamine and poly(ethylene glycol) derivate coating. This biosensor reached detection limits in the femtomolar range (6 fM) for a recombinant IBMP8-1 protein. This limit of detection is 1000-fold lower than ELISA ( $30 \mathrm{nM})$, PCR $(10 \mathrm{nM})$, and even electrochemical immunosensors $(20 \mathrm{pM})$. In addition, the assay is fast, taking less than $30 \mathrm{~min}$, and label-free. This highly sensitive biosensor still needs to be tested in human samples and optimized for PoC unit use; but so far it is the only CD biosensor that does not depend on the detection of anti-T. cruzi antibodies.

\subsection{MicroRNA}

MicroRNAs play key roles in intracellular and extracellular protein expression and regulation of biochemical pathways. They may be associated with regulating cellular apoptosis, proliferation, differentiation, metabolism, invasion, and migration. Different studies have also shown that microRNAs may serve crucial functions in the progression of numerous cancers and other diseases and 
consequently can be used as biomarkers for prognosis of disease progression [86]. For example, microRNA-208a (miR-208a) encoded by the $\alpha$-myosin heavy chain (MHC) gene has been shown to be involved in pathological cardiac growth, fibrosis, and upregulation of $\beta$-MHC expression in human dilated cardiomyopathy (DCM) [87]. It is also an early diagnostic biomarker of acute myocardial infarction (AMI) and can be used for prognosis postinfarction and disease monitoring [88].

Different microRNAs and their mRNA targets appear dysregulated in chronic Chagas disease cardiomyopathy (CCC) patients and CD murine models during acute infection [89, 90]. This year, Linhares-Lacerda et al. suggested microRNA208a could be a potential biomarker of chronic indeterminate CD (CID) [91]. Their results have shown upregulation of miR-208a in serum of CD patients in the indeterminate stage compared to chronically infected cardiac patients with DCM. This suggests the microRNA is participating in the early-onset events responsible for activation of fibrosis and cardiac dysfunction processes in CD. The same microRNA has been reported to be downregulated in the heart muscle of CD patients with CCC or DCM compared to non-infected controls [89] but upregulated in endomyocardial tissues of non-infected DCM patients [87]. Clearly a better understanding and tests in a large number of patients is needed to validate this biomarker. Nevertheless, this study opens the door to looking at microRNA as a possible analyte for CD diagnosis and prognosis.

\subsection{Omics-Based Applications}

Omics-based applications are formidable new technological resources for investigating the status of human diseases and understanding the pathophysiology of disease processes. They can generate enormous amounts of data with high fidelity thanks to recent advances in chromatography, mass spectrometry, and bioinformatics. Furthermore, omics outputs have the advantage of complementarity, enabling cross-corroboration and cross-validation [92]. In the search for biomarkers and tools for CD diagnosis and drug treatment efficacy assessment, our group is using omics applications to detect changes in the proteome, metabolome, and lipidome of CD patients compared to healthy people (Fig. 1). We are using our omics studies to build assays that could be widely employed for diagnosis, prognosis, and evaluation of treatment efficacy of new drugs. To this end, we are focusing primarily on the identification of new host markers following comparative analysis of serum samples issued from patients diagnosed with CD, treated, and followed up several years after treatment and in some cases until they reach seroreversion, the only current surrogate marker for parasitological cure.

In our earlier work involving mass spectrometry serum protein profiling studies, we identified highly sensitive and specific host protein markers (see Sect. 5.2) [50, 51]. We started our proteomics studies using MS SELDI technology for intact serum proteins analysis; in spite of the promising results, the SELDI technology did not allow the direct identification of proteins by tandem MS and had low resolution. Recently, we have used an ultrahigh-resolution quadrupole time-of-flight (UHR- 


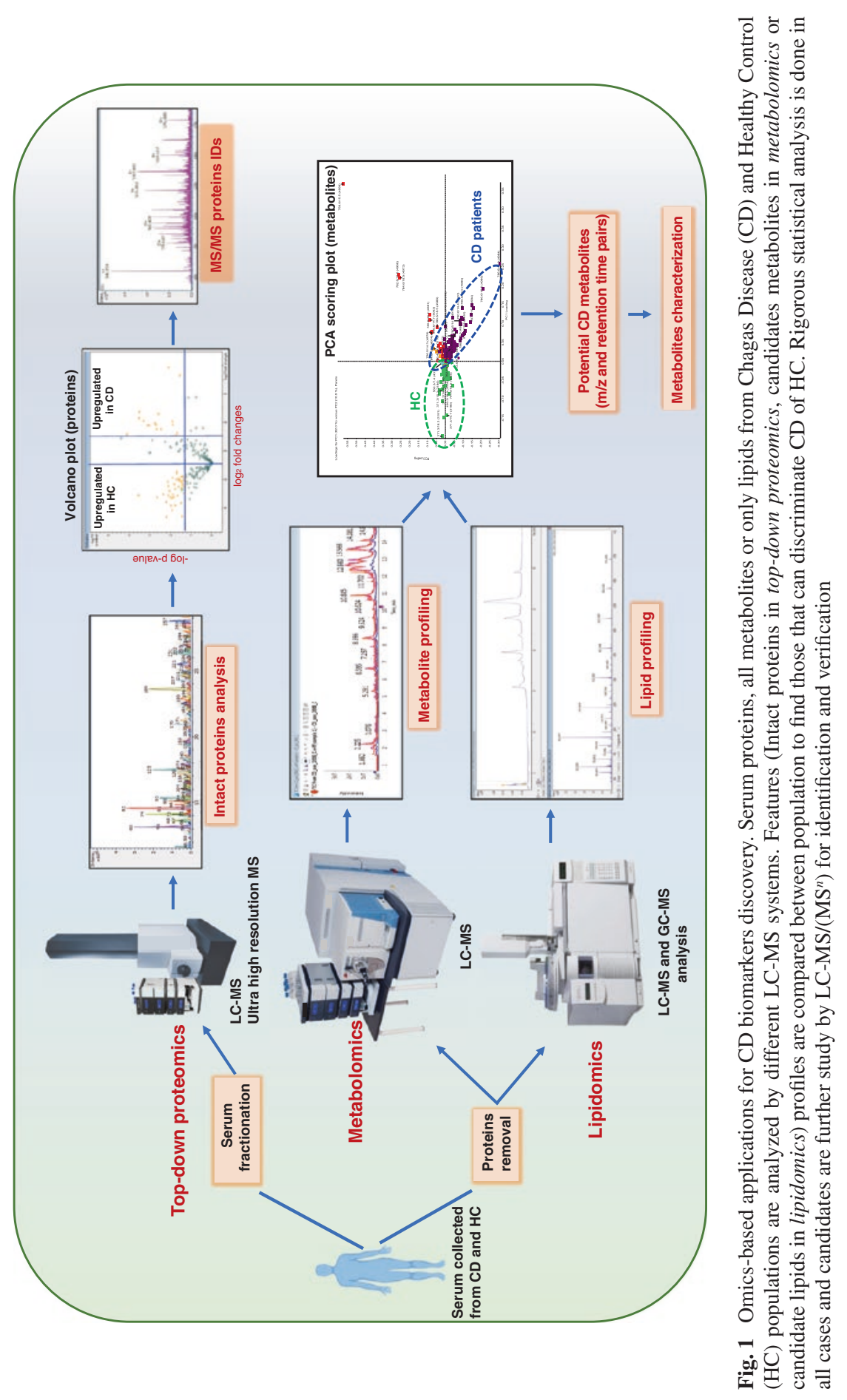


QTOF) tandem mass spectrometer coupled to ultrahigh-performance liquid chromatography (HPLC) for the same purpose. Despite the differences between MS platforms and sample processing, we have been able to reproduce our previous findings, reinforcing the robustness of our data.

In order to validate some of the protein biomarkers identified (ApoA1 and FBN fragments) using our new MS platform, we recently attempted to correlate the presence/absence of these fragments with seroreversion, which is currently the gold standard of parasitological cure in a cohort study of CD children treated with BZN. Compared to adults, seronegative conversion in children occurs in a few months to a few years, which made children's serum samples ideal for the validation of these biomarkers. Our MS analysis and specific immunoblot results showed these fragments were absent in serum at seroreversion in the entire $\mathrm{CD}$ pediatric population and in some cases at the end of BZN treatment even when children remained seropositive [93]. Although still preliminary, these data suggest that ApoA1 and FBN fragments could be used as biomarkers of parasitological cure and predict cure earlier than serology, which will make them better endpoint surrogates. Additional studies are needed to further explore the real potential of these new biomarkers, for instance, an evaluation of fragment disappearance kinetics following treatment until seroreversion.

While the proteome is of great importance, the metabolome can also provide an excellent pathophysiological understanding of disease, as proteins have functions in a range of complex metabolic reactions and their activity ultimately affects the phenotype. Metabolites (low molecular weight organic and inorganic chemicals) are simpler to study compared to proteins, are the final downstream products, and give a sensitive and rapid measurement of the phenotype. Various disease states may be characterized by a specific metabolite or a pattern of metabolite changes. Metabolomics has been successfully applied to clinical conditions including inborn errors of metabolism, cardiovascular disease, and cancer to identify biomarkers related to diagnosis, assessment of disease severity, or drug toxicity/efficacy—for a review, see [94]. Changes in the human metabolome due to T. cruzi infection are as yet unknown, and metabolites have not been explored as biomarkers for CD. Taking advantage of our high-resolution platform, we are currently studying the serum metabolite profile of CD patients, looking for biological differences after treatment and compared to a healthy population.

Finally, considering the evidence that associates $T$. cruzi with the adipose tissue, ApoA1 and with HDL and LDL modifications, as well as its interaction with LDL receptors [95], the serum lipid profile is an interesting and important metabolome component in the search for possible CD biomarkers. Lipidomics has been defined as "the full characterization of lipid molecular species and of their biological roles with respect to expression of proteins involved in lipid metabolism and function, including gene regulation." Although lipids are not used in clinical applications yet, many individual lipids have been associated with the evolution of different cancers, cardiovascular, neuropsychiatric, respiratory, and kidney diseases [96] and can provide information on disease status. Together with our metabolomics study, we are presently characterizing the lipidome in CD patients using an untargeted approach. 
We expect these holistic approaches lead to the identification of analytes that can discriminate between infected and non-infected populations.

Taken together, data issued from these different technologies will hopefully speed up the identification of markers suitable for clinical settings and proof of concept clinical studies and during drug development.

\subsection{Other Technologies}

Other no less important approaches to finding potential biomarkers rely on the identification of specific antibodies and the detection of anti-live T. cruzi antibodies by flow cytometry. To discover pathogen-specific linear B-cell epitopes from clinical samples, Carmona et al. used a highly multiplexed platform based on next-generation high-density peptide microarrays to map antibody specificities in CD [97]. In this approach, individual peptides $(\sim 180,000)$ are synthesized in situ on a glass slide at high densities, which reduces cost and allows a high-throughput and precise mapping of antibodies. After screening the arrays with antibodies purified from CD patients and HC, 2031 disease-specific peptides and 97 novel parasite antigens were identified, together with their linear B-cell epitopes [97]. Recently, Mucci et al. assessed the serological performance of 27 of these epitopes and their use in a multipeptide-based diagnostic method [98]. Seven peptides were evaluated in ELISA against 199 serum samples from CD and HC, including samples from leishmaniasis subjects. The assay showed a sensitivity of $96.3 \%$ and a specificity of $99.15 \%$ for $\mathrm{CD}$, which suggests that the peptides could be used in CD diagnosis; however, their usefulness in treatment efficacy evaluation needs to be further studied.

As mentioned in Sect. 5.1, the detection of lytic antibodies against live parasites is an alternative to the evaluation of specific antibodies. In a double-blinded study with 94 coded samples, Martins-Filho et al. found that anti-live trypomastigote antibody (ALTA) measured by flow cytometry (FC) was able to discriminate not treated (NT), treated but not cured (TNC), and treated and cured (TC) patients when using a 1:256 serum dilution [99]. In a larger study population with four different cohorts, the same group demonstrated that anti-fixed epimastigote antibody (AFEA) discriminates the clinical status of CD patients after treatment at higher serum dilutions (1/2048). FC-AFEA-IgG showed 100\% sensitivity (80.3-100\%) and specificity $(85.6-100 \%)$ with positive and negative predictive values of $100 \%$. This suggests both antibodies measured by FC are not only good enough for diagnosis and prognosis but could be useful as criteria of cure.

\section{The Way Forward}

The identification and validation of biomarkers is in general is a very challenging process. For Chagas disease, the definition of cure or clinical benefit following treatment is clearly another major challenge. In fact, in principle, we are looking for a surrogate of a surrogate for clinical benefit, i.e., looking for a surrogate of serological cure assuming that the latter is a surrogate marker for clinical cure or halting 
of progression of the disease, and searching for a surrogate marker of serological cure that allows the rapid determination of seroreversion, indicating that $T$. cruzi parasites have been eliminated from the patient's body. The identification and validation of new biomarkers for Chagas disease is, therefore, a major challenge but a serious and important one that needs to be tackled in the endeavor to develop drugs for CD. Unfortunately, no biomarkers have yet progressed to clinical validation. No correlation has been made between either the absence of T. cruzi DNA in blood (as assessed by PCR) or the reduction in titers of specific $T$. cruzi antigens or antibodies (as assessed using serological tests at specific timepoints after treatment) and seroreversion; which make these markers potential pharmacodynamic markers but not surrogates for parasitological cure at this point. Newly identified potential markers using different technology platforms, from either the host (-omics) or other antigens of the parasite (microarrays), are showing promise, but more work is needed to assess their validity. In particular, the development, optimization, and analytical verification and validation of tests for these new markers, either as single prototypes or in a multiplex, are needed before moving forward to clinical validation. It is also reasonable to believe that a set of biomarkers rather that a single "magic bullet" might be needed to ensure a correlation with parasitological cure.

Pending a robust validated multiplex assay with valid biomarkers, the challenge of being able to clinically validate these markers and obtain regulatory acceptance remains significant. In order to do this, a sufficient number of high-quality samples from well-defined cohorts are needed to move forward (biostatistical plan). The use of retrospective cohorts could be envisaged, but a large prospective study (clinical trial with long post-therapeutic follow-up of patients) might be required to verify that markers are surrogates for seroconversion. In either case, the entire Chagas community needs to make a concerted unified effort.

Acknowledgments The authors wish to thank Louise Burrows for the editing of this manuscript. The National Reference Centre for Parasitology is supported by Public Health Agency of Canada/ National Microbiology Laboratory grant WPG-6-39147 (005), the Foundation of the Montreal General Hospital, The Foundation of the McGill University Health Centre and the Research Institute of the McGill University Health Centre. The DND $i$ is grateful for its donors, public and private, who have provided funding for the DNDi since its inception in 2003. A full list of DNDi's donors can be found at http://www.dndi.org/donors/donors/. The DNDi received financial support from the following donors: the Department for International Development (DFID), UK; Reconstruction Credit Institution-Federal Ministry of Education and Research (KfW-BMBF), Germany; Directorate-General for International Cooperation (DGIS), the Netherlands; Swiss Agency for Development and Cooperation (SDC), Switzerland; and Médecins Sans Frontières (Doctors Without Borders), international. The donors had no role in the study design, data collection and analysis, decision to publish, or preparation of the manuscript.

\section{References}

1. Pinazo M-J, Thomas M-C, Bustamante J, ICd A, Lopez M-C, Gascon J. Biomarkers of therapeutic responses in chronic Chagas disease: state of the art and future perspectives. Mem Inst Oswaldo Cruz. 2015;110:422-32.

2. Pinazo MJ, Thomas MC, Bua J, Perrone A, Schijman AG, Viotti RJ, Ramsey JM, Ribeiro I, Sosa-Estani S, Lopez MC, Gascon J. Biological markers for evaluating therapeutic efficacy in 
Chagas disease, a systematic review. Expert Rev Anti-Infect Ther. 2014;12:479-96. https:// doi.org/10.1586/14787210.2014.899150.

3. Pinho RT, Waghabi MC, Cardillo F, Mengel J, Antas PR. Scrutinizing the biomarkers for the neglected Chagas disease: how remarkable! Front Immunol. 2016;7:306. https://doi. org/10.3389/fimmu.2016.00306.

4. Chagas C. Nova tripanozomiaze humana: estudos sobre a morfolojia e o ciclo evolutivo do Schizotrypanum cruzi n. gen., n. sp., ajente etiolojico de nova entidade morbida do homem. Mem Inst Oswaldo Cruz. 1909;1:159-218.

5. Schmunis GA, Yadon ZE. Chagas disease: a Latin American health problem becoming a world health problem. Acta Trop. 2010;115:14-21.

6. Meymandi SK, Hernandez S, Forsyth CJ. A community-based screening program for Chagas disease in the USA. Trends Parasitol. 2017;33:828-31.

7. Requena-Méndez A, Aldasoro E, de Lazzari E, Sicuri E, Brown M, Moore DA, Gascon J, Muñoz J. Prevalence of Chagas disease in Latin-American migrants living in Europe: a systematic review and meta-analysis. PLoS Negl Trop Dis. 2015;9:e0003540.

8. Jackson Y, Pinto A, Pett S. Chagas disease in Australia and New Zealand: risks and needs for public health interventions. Tropical Med Int Health. 2014;19:212-8.

9. Moolani Y, Bukhman G, Hotez PJ. Neglected tropical diseases as hidden causes of cardiovascular disease. PLoS Negl Trop Dis. 2012;6:e1499.

10. WHO. Chagas disease. Geneva: World Health Organization; 2018. www.who.int/mediacentre/ factsheets/fs340/en/. Accessed 16 Feb 2018

11. Cucunubá ZM, Okuwoga O, Basáñez M-G, Nouvellet P. Increased mortality attributed to Chagas disease: a systematic review and meta-analysis. Parasit Vectors. 2016;9:42.

12. Urbina JA. The long road towards a safe and effective treatment of chronic Chagas disease. Lancet Infect Dis. 2018;18:363-5.

13. Ayub-Ferreira SM, Mangini S, Issa VS, Cruz FD, Bacal F, Guimarães GV, Chizzola PR, Conceição-Souza GE, Marcondes-Braga FG, Bocchi EA. Mode of death on Chagas heart disease: comparison with other etiologies. a subanalysis of the REMADHE prospective trial. PLoS Negl Trop Dis. 2013;74:e2176.

14. Brum-Soares L, Cubides J-C, Burgos I, Monroy C, Castillo L, González S, Viñas PA, Urrutia PPP. High seroconversion rates in Trypanosoma cruzi chronic infection treated with benznidazole in people under 16 years in Guatemala. Rev Soc Bras Med Trop. 2016;49:721-7.

15. Olivera MJ, Cucunubá ZM, Álvarez CA, Nicholls RS. Safety profile of nifurtimox and treatment interruption for chronic Chagas disease in Colombian adults. Am J Trop Med Hyg. 2015;93:1224-30.

16. Cançado JR. Criteria of Chagas disease cure. Mem Inst Oswaldo Cruz. 1999;94:331-5.

17. de Lana M, Martins-Filho OA. Revisiting the posttherapeutic cure criterion in Chagas disease: time for new methods, more questions, doubts, and polemics or time to change old concepts? Biomed Res Int. 2015;2015:652985. https://doi.org/10.1155/2015/652985.

18. Temple R. A regulatory authority's opinion about surrogate endpoints. In: Nimmo WS, Tuck GT, editors. Clinical measurement in drug evaluation. New York, NY: Wiley; 1995. p. 1-22.

19. Balouz V, Agüero F, Buscaglia CA. Chagas disease diagnostic applications: present knowledge and future steps. In: Advances in parasitology, vol. 97. New York City, NY: Elsevier; 2017. p. 1-45.

20. FDA. FDA approves first U.S. treatment for Chagas disease. www.fda.gov/NewsEvents/ Newsroom/PressAnnouncements/ucm573942.htm. Accessed 16 Feb 2018.

21. Sosa ES. Soluble platelet selectin (sP-selectin) and soluble vascular cell adhesion molecule-1 (sVCAM-1) decrease during therapy with benznidazole in children with indeterminate form of Chagas' disease. Clin Exp Immunol. 1999;118:423-7.

22. de Andrade ALSS, Zicker F, de Oliveira RM, e Silva SA, Luquetti A, Travassos LR, Almeida IC, de Andrade SS, de Andrade JG, Martelli CM. Randomised trial of efficacy of benznidazole in treatment of early Trypanosoma cruzi infection. Lancet. 1996;348:1407-13.

23. Henao-Martínez AF, Schwartz DA, Yang IV. Chagasic cardiomyopathy, from acute to chronic: is this mediated by host susceptibility factors? Trans R Soc Trop Med Hyg. 2012;106:521-7. 
24. Deng X, Sabino EC, Cunha-Neto E, Ribeiro AL, Ianni B, Mady C, Busch MP, Seielstad M. Genome wide association study (GWAS) of Chagas cardiomyopathy in Trypanosoma cruzi seropositive subjects. PLoS One. 2013;8:e79629.

25. Del Puerto F, Nishizawa JE, Kikuchi M, Roca Y, Avilas C, Gianella A, Lora J, Velarde FUG, Miura S, Komiya N. Protective human leucocyte antigen haplotype, HLA-DRB1*01-B*14, against chronic Chagas disease in Bolivia. PLoS Negl Trop Dis. 2012;6:e1587.

26. Clipman SJ, Henderson-Frost J, Fu KY, Bern C, Flores J, Gilman RH. Genetic association study of NLRP1, CARD, and CASP1 inflammasome genes with chronic Chagas cardiomyopathy among Trypanosoma cruzi seropositive patients in Bolivia. PLoS One. 2018;13:e0192378.

27. Nohaile M. The biomarker is not the end. Drug Discov Today. 2011;16:878-83.

28. Porrás AI, Yadon ZE, Altcheh J, Britto C, Chaves GC, Flevaud L, Martins-Filho OA, Ribeiro I, Schijman AG, Shikanai-Yasuda MA. Target product profile (TPP) for Chagas disease point-ofcare diagnosis and assessment of response to treatment. PLoS Negl Trop Dis. 2015;9:e0003697.

29. Tuck MK, Chan DW, Chia D, Godwin AK, Grizzle WE, Krueger KE, Rom W, Sanda M, Sorbara L, Stass S. Standard operating procedures for serum and plasma collection: early detection research network consensus statement standard operating procedure integration working group. J Proteome Res. 2008;8:113-7.

30. Omenn GS, States DJ, Adamski M, Blackwell TW, Menon R, Hermjakob H, Apweiler R, Haab BB, Simpson RJ, Eddes JS. Overview of the HUPO Plasma Proteome Project: Results from the pilot phase with 35 collaborating laboratories and multiple analytical groups, generating a core dataset of 3020 proteins and a publicly-available database. Proteomics. 2005;5:3226-45.

31. Requena-Méndez A, López MC, Angheben A, Izquierdo L, Ribeiro I, Pinazo M-J, Gascon J, Muñoz J. Evaluating Chagas disease progression and cure through blood-derived biomarkers: a systematic review. Expert Rev Anti-Infect Ther. 2013;11:957-76.

32. Altcheh J, Corral R, Biancardi M, Freilij H. Anti-F2/3 antibodies as cure marker in children with congenital Trypanosoma cruzi infection. Medicina. 2003;63:37-40.

33. Cancado JR. Long term evaluation of etiological treatment of chagas disease with benznidazole. Rev Inst Med Trop Sao Paulo. 2002;44:29-37.

34. de Apparecida Levy AM, Boainain E, Kloetzel JK. In situ indirect fluorescent antibody: a new specific test to detect ongoing chagasic infections. J Clin Lab Anal. 1996;10:98-103.

35. Andrade ALS, Martelli CM, Oliveira RM, Silva SA, Aires AI, Soussumi LM, Covas DT, Silva LS, Andrade JG, Travassos LR. Benznidazole efficacy among Trypanosoma cruzi-infected adolescents after a six-year follow-up. Am J Trop Med Hyg. 2004;71:594-7.

36. Pinazo M-J, de Jesus Posada E, Izquierdo L, Tassies D, Marques A-F, de Lazzari E, Aldasoro E, Muñoz J, Abras A, Tebar S. Altered hypercoagulability factors in patients with chronic Chagas disease: potential biomarkers of therapeutic response. PLoS Negl Trop Dis. 2016;10:e0004269.

37. Almeida IC, Covas DT, Soussumi LM, Travassos LR. A highly sensitive and specific chemiluminescent enzyme-linked immunosorbent assay for diagnosis of active Trypanosoma cruzi infection. Transfusion. 1997;37:850-7.

38. Negrette OS, Valdéz FJS, Lacunza CD, Bustos MFG, Mora MC, Uncos AD, Basombrío MÁ. Serological evaluation of specific-antibody levels in patients treated for chronic Chagas' disease. Clin Vaccine Immunol. 2008;15:297-302.

39. Fabbro DL, Olivera V, Bizai ML, Denner S, Diez C, Mancipar I, Streiger M, Arias E, del Barco M, Mendicino D. Humoral immune response against P2 $\beta$ from Trypanosoma cruzi in persons with chronic Chagas disease: its relationship with treatment against parasites and myocardial damage. Am J Trop Med Hyg. 2011;84:575-80.

40. Fernández-Villegas A, Pinazo MJ, Marañón C, Thomas MC, Posada E, Carrilero B, Segovia M, Gascon J, López MC. Short-term follow-up of chagasic patients after benznidazole treatment using multiple serological markers. BMC Infect Dis. 2011;11:206.

41. Flechas ID, Cuellar A, Cucunubá ZM, Rosas F, Velasco V, Steindel M, del Carmen Thomas M, López MC, González JM, Puerta CJ. Characterising the KMP-11 and HSP-70 recombinant antigens' humoral immune response profile in chagasic patients. BMC Infect Dis. 2009;9:186.

42. Krettli AU. The utility of anti-trypomastigote lytic antibodies for determining cure of Trypanosoma cruzi infections in treated patients: an overview and perspectives. Mem Inst Oswaldo Cruz. 2009;104:142-51. 
43. Krautz GM, Galvão L, Cancado JR, Guevara-Espinoza A, Ouaissi A, Krettli AU. Use of a 24-kilodalton Trypanosoma cruzi recombinant protein to monitor cure of human Chagas' disease. J Clin Microbiol. 1995;33:2086-90.

44. Estani SS, Segura EL, Ruiz AM, Velazquez E, Porcel BM, Yampotis C. Efficacy of chemotherapy with benznidazole in children in the indeterminate phase of Chagas' disease. Am J Trop Med Hyg. 1998;59:526-9.

45. Fabbro D, Velazquez E, Bizai ML, Denner S, Olivera V, Arias E, Pravia C, Ruiz AM. Evaluation of the ELISA-F29 test as an early marker of therapeutic efficacy in adults with chronic Chagas disease. Rev Inst Med Trop Sao Paulo. 2013;55:167-72.

46. Cooley G, Etheridge RD, Boehlke C, Bundy B, Weatherly DB, Minning T, Haney M, Postan M, Laucella S, Tarleton RL. High throughput selection of effective serodiagnostics for Trypanosoma cruzi infection. PLoS Negl Trop Dis. 2008;2:e316.

47. Viotti R, Vigliano C, Álvarez MG, Lococo B, Petti M, Bertocchi G, Armenti A, De Rissio AM, Cooley G, Tarleton R. Impact of aetiological treatment on conventional and multiplex serology in chronic Chagas disease. PLoS Negl Trop Dis. 2011;5:e1314.

48. Meira WS, Galvão LM, Gontijo ED, Machado-Coelho GL, Norris KA, Chiari E. Use of the Trypanosoma cruzi recombinant complement regulatory protein to evaluate therapeutic efficacy following treatment of chronic chagasic patients. J Clin Microbiol. 2004;42:707-12.

49. Zrein M, Granjon E, Gueyffier L, Caillaudeau J, Liehl P, Pottel H, Cardoso CS, Oliveira CDL, de Oliveira LC, Lee T-H. A novel antibody surrogate biomarker to monitor parasite persistence in Trypanosoma cruzi-infected patients. PLoS Negl Trop Dis. 2018;12:e006226.

50. Ndao M, Spithill TW, Caffrey R, Li H, Podust VN, Perichon R, Santamaria C, Ache A, Duncan M, Powell MR, Ward BJ. Identification of novel diagnostic serum biomarkers for Chagas' disease in asymptomatic subjects by mass spectrometric profiling. J Clin Microbiol. 2010;48:1139-49. doi:JCM.02207-09

51. Santamaria C, Chatelain E, Jackson Y, Miao Q, Ward BJ, Chappuis F, Ndao M. Serum biomarkers predictive of cure in Chagas disease patients after nifurtimox treatment. BMC Infect Dis. 2014;14:302. https://doi.org/10.1186/1471-2334-14-302.

52. Pinazo M-J, Tassies D, Muñoz J, Fisa R, de Jesús Posada E, Monteagudo J, Ayala E, Gállego M, Reverter J-C, Gascon J. Hypercoagulability biomarkers in Trypanosoma cruzi-infected patients. Thromb Haemost. 2011;106:617-23.

53. Laucella SA, Mazliah DP, Bertocchi G, Alvarez MG, Cooley G, Viotti R, Albareda MC, Lococo B, Postan M, Armenti A. Changes in Trypanosoma cruzi-specific immune responses after treatment: surrogate markers of treatment efficacy. Clin Infect Dis. 2009;49:1675-84.

54. Dutra WO, Cançado JR, Pereira ME, Brígido-Nunes R, Galvão L, Colley DG, Brener Z, Gazzinelli G, Carvalho-Parra JF. Influence of parasite presence on the immunologic profile of peripheral blood mononuclear cells from chagasic patients after specific drug therapy. Parasite Immunol. 1996;18:579-85.

55. Sathler-Avelar R, Vitelli-Avelar DM, Massara RL, de Lana M, Dias JCP, Teixeira-Carvalho A, Elói-Santos SM, Martins-Filho OA. Etiological treatment during early chronic indeterminate Chagas disease incites an activated status on innate and adaptive immunity associated with a type 1-modulated cytokine pattern. Microbes Infect. 2008;10:103-13.

56. Argüello RJ, Albareda MC, Alvarez MG, Bertocchi G, Armenti AH, Vigliano C, Meckert PC, Tarleton RL, Laucella SA. Inhibitory receptors are expressed by Trypanosoma cruzispecific effector T cells and in hearts of subjects with chronic Chagas disease. PLoS One. 2012;7:e35966.

57. Sguassero Y, Cuesta CB, Roberts KN, Hicks E, Comandé D, Ciapponi A, Sosa-Estani S. Course of chronic Trypanosoma cruzi infection after treatment based on parasitological and serological tests: a systematic review of follow-up studies. PLoS One. 2015;10:e0139363.

58. Britto CC. Usefulness of PCR-based assays to assess drug efficacy in Chagas disease chemotherapy: value and limitations. Mem Inst Oswaldo Cruz. 2009;104:122-35.

59. Wei B, Chen L, Kibukawa M, Kang J, Waskin H, Marton M. Development of a PCR assay to detect low level Trypanosoma cruzi in blood specimens collected with PAXgene blood DNA tubes for clinical trials treating Chagas disease. PLoS Negl Trop Dis. 2016;10:e0005146. 
60. Morillo CA, Waskin H, Sosa-Estani S, del Carmen Bangher M, Cuneo C, Milesi R, Mallagray M, Apt W, Beloscar J, Gascon J. Benznidazole and posaconazole in eliminating parasites in asymptomatic T. cruzi carriers: the STOP-CHAGAS trial. J Am Coll Cardiol. 2017;69:939-47.

61. Eiro C, Melisa D, Alvarez MG, Cooley G, Viotti RJ, Bertocchi GL, Lococo B, Albareda MC, De Rissio AM, Natale MA. The significance of discordant serology in Chagas disease: enhanced T-cell immunity to Trypanosoma cruzi in serodiscordant subjects. Front Immunol. 2017;8:1141.

62. Moure Z, Angheben A, Molina I, Gobbi F, Espasa M, Anselmi M, Salvador F, Tais S, SánchezMontalvá A, Pumarola T. Serodiscordance in chronic Chagas disease diagnosis: a real problem in non-endemic countries. Clin Microbiol Infect. 2016;22:788-92.

63. Moure Z, Sulleiro E, Iniesta L, Guillen C, Molina I, Alcover MM, Riera C, Pumarola T, Fisa R. The challenge of discordant serology in Chagas disease: the role of two confirmatory techniques in inconclusive cases. Acta Trop. 2018;185:144-8. https://doi.org/10.1016/j. actatropica.2018.05.010.

64. Cardoso CS, Sabino EC, Oliveira CDL, de Oliveira LC, Ferreira AM, Cunha-Neto E, Bierrenbach AL, Ferreira JE, Haikal DSA, Reingold AL. Longitudinal study of patients with chronic Chagas cardiomyopathy in Brazil (SaMi-Trop project): a cohort profile. BMJ Open. 2016;6:e11181.

65. Galvão L, Nunes R, Cançado J, Brener Z, Krettli A. Lytic antibody titre as a means of assessing cure after treatment of Chagas disease: a 10 years follow-up study. Trans R Soc Trop Med Hyg. 1993;87:220-3.

66. Ndao M, Rainczuk A, Rioux M-C, Spithill TW, Ward BJ. Is SELDI-TOF a valid tool for diagnostic biomarkers? Trends Parasitol. 2010;26:561-7.

67. Ndao M. Biomarker discovery in serum/plasma using surface enhanced laser desorption ionization time of flight (SELDI-TOF) mass spectrometry. In: Clarke CH, Bankert McCarthy DL, editors. SELDI-TOF mass spectrometry. New York, NY: Springer; 2012. p. 67-79.

68. Gomes J, Bahia-Oliveira L, Rocha M, Martins-Filho O, Gazzinelli G, Correa-Oliveira R. Evidence that development of severe cardiomyopathy in human Chagas' disease is due to a Th1-specific immune response. Infect Immun. 2003;71:1185-93.

69. Bustamante JM, Bixby LM, Tarleton RL. Drug-induced cure drives conversion to a stable and protective CD8+ T central memory response in chronic Chagas disease. Nat Med. 2008; 14:542.

70. Bustamante JM, Craft JM, Crowe BD, Ketchie SA, Tarleton RL. New, combined, and reduced dosing treatment protocols cure Trypanosoma cruzi infection in mice. J Infect Dis. 2013;209:150-62.

71. Gold L, Ayers D, Bertino J, Bock C, Bock A, Brody EN, Carter J, Dalby AB, Eaton BE, Fitzwater T. Aptamer-based multiplexed proteomic technology for biomarker discovery. PLoS One. 2010;5:e15004.

72. Morris KN, Jensen KB, Julin CM, Weil M, Gold L. High affinity ligands from in vitro selection: complex targets. Proc Natl Acad Sci. 95(6):2902-7.

73. Shamah SM, Healy JM, Cload ST. Complex target SELEX. Acc Chem Res (1998). 2008;41:130-8.

74. Nagarkatti R, Bist V, Sun S, de Araujo FF, Nakhasi HL, Debrabant A. Development of an aptamer-based concentration method for the detection of Trypanosoma cruzi in blood. PLoS One. 2012;7:e43533.

75. Nagarkatti R, de Araujo FF, Gupta C, Debrabant A. Aptamer based, non-PCR, non-serological detection of Chagas disease biomarkers in Trypanosoma cruzi infected mice. PLoS Negl Trop Dis. 2014;8:e2650.

76. de Araujo FF, Nagarkatti R, Gupta C, Marino AP, Debrabant A. Aptamer-based detection of disease biomarkers in mouse models for chagas drug discovery. PLoS Negl Trop Dis. 2015;9:e3451.

77. Sin ML, Mach KE, Wong PK, Liao JC. Advances and challenges in biosensor-based diagnosis of infectious diseases. Expert Rev Mol Diagn. 2014;14:225-44.

78. Rocha-Gaso M-I, Villarreal-Gómez L-J, Beyssen D, Sarry F, Reyna M-A, Ibarra-Cerdeña C-N. Biosensors to diagnose Chagas disease: a brief review. Sensors. 2017;17:2629. 
79. Pereira SV, Bertolino FA, Fernández-Baldo MA, Messina GA, Salinas E, Sanz MI, Raba J. A microfluidic device based on a screen-printed carbon electrode with electrodeposited gold nanoparticles for the detection of $\operatorname{IgG}$ anti-Trypanosoma cruzi antibodies. Analyst. 2011;136:4745-51.

80. Regiart M, Pereira SV, Bertolino FA, Garcia CD, Raba J, Aranda PR. An electrochemical immunosensor for anti-T. cruzi IgM antibodies, a biomarker for congenital Chagas disease, using a screen-printed electrode modified with gold nanoparticles and functionalized with shed acute phase antigen. Microchim Acta. 2016;183:1203-10.

81. Marcipar IS, Lagier CM. Advances in serological diagnosis of Chagas' disease by using recombinant proteins. In: Current topics in tropical medicine. London: InTechOpen; 2012. p. 273-92. https://doi.org/10.5772/28100.

82. Cortina ME, Melli LJ, Roberti M, Mass M, Longinotti G, Tropea S, Lloret P, Serantes DAR, Salomón F, Lloret M. Electrochemical magnetic microbeads-based biosensor for point-of-care serodiagnosis of infectious diseases. Biosens Bioelectron. 2016;80:24-33.

83. Luz JG, Souto DE, Machado-Assis GF, de Lana M, Kubota LT, Luz RC, Damos FS, Martins HR. Development and evaluation of a SPR-based immunosensor for detection of antiTrypanosoma cruzi antibodies in human serum. Sensors Actuators B Chem. 2015;212:287-96.

84. Phillips KS, Cheng Q. Recent advances in surface plasmon resonance based techniques for bioanalysis. Anal Bioanal Chem. 2007;387:1831-40.

85. Janissen R, Sahoo PK, Santos CA, da Silva AM, von Zuben AA, Souto DE, Costa AD, Celedon P, Zanchin NI, Almeida DB. InP nanowire biosensor with tailored biofunctionalization: ultrasensitive and highly selective disease biomarker detection. Nano Lett. 2017;17:5938-49.

86. Wang J, Chen J, Sen S. MicroRNA as biomarkers and diagnostics. J Cell Physiol. 2016;231:25-30.

87. Satoh M, Minami Y, Takahashi Y, Tabuchi T, Nakamura M. Expression of microRNA-208 is associated with adverse clinical outcomes in human dilated cardiomyopathy. J Card Fail. 2010;16:404-10.

88. Wang C, Jing Q. Non-coding RNAs as biomarkers for acute myocardial infarction. Acta Pharmacol Sin. 2018; https://doi.org/10.1038/aps.2017.205.

89. Ferreira LRP, Ferreira FM, Laugier L, Cabantous S, Navarro IC, Cândido DS, Rigaud VC, Real JM, Pereira GV, Pereira IR. Integration of miRNA and gene expression profiles suggest a role for miRNAs in the pathobiological processes of acute Trypanosoma cruzi infection. Sci Rep. 2017;7:17990.

90. Ferreira LRP, Frade AF, Santos RHB, Teixeira PC, Baron MA, Navarro IC, Benvenuti LA, Fiorelli AI, Bocchi EA, Stolf NA. MicroRNAs miR-1, miR-133a, miR-133b, miR-208a and miR-208b are dysregulated in chronic Chagas disease cardiomyopathy. Int J Cardiol. 2014;175:409-17.

91. Linhares-Lacerda L, Granato A, Gomes-Neto JF, Conde L, Freire-de-Lima L, de Freitas EO, Freire-de-Lima CG, Coutinho Barroso SP, Jorge de Alcântara Guerra R, Pedrosa RC. Circulating plasma microRNA-208a as potential biomarker of chronic indeterminate phase of Chagas disease. Front Microbiol. 2018;9:269.

92. Matthews H, Hanison J, Nirmalan N. "Omics"-informed drug and biomarker discovery: opportunities, challenges and future perspectives. Proteomes. 2016;4:28.

93. Ruiz-Lancheros E, Chatelain E, Bournissen F, Moroni S, Moscatelli G, Altcheh J, Ndao M. Surrogate biomarkers of cure for Chagas' disease in children treated with benznidazole. Open Forum Infect Dis. In press 2018. Doi: https://doi.org/10.1093/ofid/ofy236

94. Mamas M, Dunn WB, Neyses L, Goodacre R. The role of metabolites and metabolomics in clinically applicable biomarkers of disease. Arch Toxicol. 2011;85:5-17.

95. Miao Q, Ndao M. Trypanosoma cruzi infection and host lipid metabolism. Mediat Inflamm. 2014;2014:902038. https://doi.org/10.1155/2014/902038.

96. Zhao Y-Y, Cheng X-L, Lin R-C. Lipidomics applications for discovering biomarkers of diseases in clinical chemistry. Int Rev Cell Mol Biol. 2014;313:1-26. 
97. Carmona SJ, Nielsen M, Schafer-Nielsen C, Mucci J, Altcheh J, Balouz V, Tekiel V, Frasch AC, Campetella O, Buscaglia CA. Towards high-throughput immunomics for infectious diseases: use of next-generation peptide microarrays for rapid discovery and mapping of antigenic determinants. Mol Cell Proteomics. 2015;14:1871-84.

98. Mucci J, Carmona SJ, Volcovich R, Altcheh J, Bracamonte E, Marco JD, Nielsen M, Buscaglia CA, Agüero F. Next-generation ELISA diagnostic assay for Chagas disease based on the combination of short peptidic epitopes. PLoS Negl Trop Dis. 2017;11:e005972.

99. Martins-Filho OA, Eloi-Santos SM, Carvalho AT, Oliveira RC, Rassi A, Luquetti AO, Rassi GG, Brener Z. Double-blind study to evaluate flow cytometry analysis of anti-live trypomastigote antibodies for monitoring treatment efficacy in cases of human Chagas' disease. Clin Diagn Lab Immunol. 2002;9:1107-13.

Open Access This chapter is licensed under the terms of the Creative Commons Attribution 4.0 International License (http://creativecommons.org/licenses/by/4.0/), which permits use, sharing, adaptation, distribution and reproduction in any medium or format, as long as you give appropriate credit to the original author(s) and the source, provide a link to the Creative Commons license and indicate if changes were made.

The images or other third party material in this chapter are included in the chapter's Creative Commons license, unless indicated otherwise in a credit line to the material. If material is not included in the chapter's Creative Commons license and your intended use is not permitted by statutory regulation or exceeds the permitted use, you will need to obtain permission directly from the copyright holder. 